\title{
O sujeito urbano escolarizado e as políticas de língua(s): de pobre a excluído ${ }^{1}$
}

\author{
Mariza Vieira da Silva ${ }^{2}$
}

\begin{abstract}
Resumo: Neste artigo, visamos a compreender os processos discursivos que estruturam a posição sujeito urbano escolarizado e seus efeitos no que diz respeito às políticas de língua(s), tomando como trajeto de leitura, sob a perspectiva da análise de discurso pechetiana, os termos/noções pobre e excluído, e tendo como referência para a construção de nosso arquivo o século XIX e a segunda metade do século XX. O trabalho permitiu-nos explicitar contradições presentes nos processos de nomeação, de construção de referentes discursivos, de individuação do sujeito, observando o confronto que aí se dá do simbólico com o político.
\end{abstract}

Palavras-chave: Sujeito urbano escolarizado. Pobre. Excluído. Análise de Discurso.

\begin{abstract}
In this paper, we aim to understand the discursive processes which structure the schooled urban subject position and its effects with regard to language policy(ies), taking as a reading path, from the perspective of the Pechetian discourse analysis, the terms/notions of poor and excluded, and having as reference for the construction of our data the second half of the nineteenth century and that of the twentieth century. The work allowed us to explain the contradictions present in the processes of naming, of constructing discursive referents, of individuating the subject, observing the confrontation between the symbolic and the political therein.
\end{abstract}

Keywords: Schooled urban subject. Poor. Excluded. Discourse Analysis.

Résumé: Dans cet article, nous cherchons à comprendre les processus discursifs qui structurent la position du sujet urbain scolarisé et leurs effets par rapport aux politiques linguistiques, en prenant comme trajet de lecture, du point de vue de l'analyse de discours pechetienne, les termes et notions pauvre et exclu, et ayant comme référence pour la construction de nos archives le XIXe siècle et la seconde moitié du XXe siècle. Le travail nous a permis d'expliciter les contradictions présentes dans les processus de dénomination, de construction de référents discursifs, d'individuation de sujet, observant la confrontation entre le symbolique et le politique.

Mots-clés: Sujet urbain scolarisé. Pauvre. Exclu. Analyse de Discours.

\footnotetext{
${ }^{1}$ Texto apresentado no Simpósio O político-ideológico no ensino de língua(s), sob a coordenação de Claudia Pfeiffer e Marisa Grigoletto, no VIII SEAD - Seminário de Estudos em Análise do Discurso, realizado na Universidade Federal de Pernambuco (UFPE), no período de 12 a 15 de setembro de 2017.

2 Doutora em Linguística pela Universidade Estadual de Campinas com pós-doutorado em "História das Ideias Linguísticas" na École Supérieure Lettres et Sciences Humaines em Lyon/França. Professora aposentada; atualmente, pesquisadora vinculada ao Laboratório de Estudos Urbanos LABEURB/NUDECRI/UNICAMP.
} 


\section{Introdução}

A história da difusão da escrita está ligada à história da cidade, sendo que seu aprendizado se desencadeia e se desenvolve em condições de produção heterogêneas, em relação aos modos como se dão os processos de urbanização em conjunturas historicamente determinadas. Os processos discursivos (PÊCHEUX, 1988) presentes na escolarização de uma língua tida, imaginariamente, como comum a todos os cidadãos de uma nação, têm na noção de sujeito o que realiza as contradições da linguística entre unidade e diversidade, e as da educação entre indivíduo e sociedade.

Nesse sentido, nosso objetivo, neste artigo, é explicitar e discutir processos discursivos que constituem/estruturam a posição sujeito urbano escolarizado (PFEIFFER, 1998) e seus efeitos no que diz respeito às políticas de língua(s), tomando como trajeto de leitura, sob a perspectiva da Análise de Discurso pechetiana, os termos/noções pobre e excluído, e observando o confronto que aí se dá do simbólico com o político, marcado pela divisão do sentido, do sujeito, da sociedade.

Buscamos, assim, ampliar nossa compreensão sobre os diferentes processos de significação e de individuação do sujeito que comandam a textualização das políticas públicas de educação e de línguas, das teorias educacionais e linguísticas e das práticas escolares e sociais, levando em consideração os espaços de heterogeneidade nos quais funcionam as contradições. Nesse sentido, a constituição de nosso arquivo se deu em referência a dois momentos históricos, considerando certas categorias de análise: a segunda metade do século XIX, quando acontecimentos como a Independência, a Abolição da Escravatura e a Proclamação da República produzem movimentos político-sociais decisivos em relação à urbanização e à escolarização da população brasileira, configurando a posição sujeito livre e pobre; e a segunda metade do século XX, em que se inicia efetivamente a universalização da Educação Fundamental em meio a uma crescente e complexa urbanização, em que o efeito sujeito excluído produz-se no centro da cena enunciativa de diferentes discursividades pela inscrição dos efeitos linguísticos materiais na história (GADET; PÊCHEUX, 2004) em que estão implicadas as noções de direito, de democracia, de cidadania, de desigualdade, em 
determinadas condições materiais de existência de uma sociedade extremamente desigual como a nossa. Nesse momento, sob o ideário do capital humano, em uma conjuntura econômica desenvolvimentista, o problema da desigualdade de classe social desloca-se para a desigualdade educacional, ficando, então, a educação, a escola (logo, o ensino de língua(s)) como principais responsáveis pela superação das desigualdades sociais e pelo progresso do País.

\section{Exclusão-inclusão: ideologia, assujeitamento}

A inclusão, como categoria analítica, surge na segunda metade do século XX para administrar a desigualdade social persistente em diferentes domínios. Os nossos arquivos referentes à segunda metade do século XX mostram que a partir principalmente da década de 1960, no Brasil, acentua-se a migração rural para os centros urbanos, provocando a necessidade da expansão da rede escolar, e trazendo, como um problema social, educacional e linguístico a ser resolvido por políticas públicas e pela escola, um aluno diferente, que fala diferente, advindo de segmentos das classes populares - negros, pardos, migrantes do campo, trabalhadores manuais, moradores da periferia, alunos fora da faixa etária legal -, bem como professores diferentes, dada a precarização do trabalho docente e a formação do professor feita, em grande parte, por universidades particulares e faculdades isoladas nem sempre qualificadas. Por outro lado, a pobreza se movimenta, desloca-se em um novo espaço físico e simbólico que demanda escolarização. E os pobres lutam por ela.

Os sentidos de e sobre a exclusão-inclusão - um par em que os sentidos se engendram em sua historicidade - em termos de limites e de fronteiras sempre em movimento, passam a circular, no Brasil, a partir dos anos de 1990, no âmbito de políticas públicas, criando condições para que o sujeito urbano escolarizado se individualize em relação ao Estado e suas instituições, de modo homogeneizante enquanto grupo social, e possa ser identificado, avaliado, controlado.

O discurso - "efeito de sentidos entre locutores" (PÊCHEUX, 1990) - sobre o pobre e o excluído funciona em condições de produção específicas em que estão 
compreendidos os interlocutores, a situação de enunciação, mas também o contexto histórico mais amplo, a memória, uma memória discursiva relacionando dizeres ditos, não ditos, já ditos - muitas vezes esquecidos e que retornam sob a forma de préconstruídos. Lembremos com Pêcheux (1988, p. 162) que "algo fala" sempre antes, em outro lugar e independentemente em uma conjuntura dada. O que significa que esses termos e noções, analisados em sua historicidade, ajudam-nos a compreender do que estamos falando quando falamos de pobreza e de exclusão.

Os sentidos de exclusão-inclusão constituem-se, pois, em um novo espaçotempo urbano simbólico e político, ao mesmo tempo em que a posição sujeito escolarizado e seus efeitos em termos de limites e fronteiras, sempre em movimento, que individualizam, identificam esse sujeito em relação ao Estado e à escola. Uma ida ao dicionário, um discurso e uma tecnologia linguística (AUROUX, 1992), criam condições para que comecemos a atravessar a transparência da linguagem e a literalidade do sentido, bem como nesses limites e fronteiras como lugar de trabalho de contradições, de funcionamento da ideologia que, lembremos, não é conteúdo, mas o mecanismo de produzir "x" (ORLANDI, 1996), em que está sempre presente a divisão, seja a do sujeito, a do sentido, a da sociedade, como já dissemos.

Dessa ida ao Grande Dicionário Houaiss (online), pudemos observar marcas de um funcionamento linguístico-discursivo que evidenciam o que Pêcheux chama de lutas ideológicas de movimento, "não como lutas entre classes constituídas como tais, mas, em vez disso, como uma série de disputas e embates móveis..." (PÊCHEUX; GADET, 2011, p. 97). Funcionamento este centrado em um movimento entre ser/estar "dentro" ou "fora" de algo, por motivos externos ou internos ao sujeito.

Podemos apreender esse movimento pela estrutura do verbete e pelas relações de intertextualidade e de interdiscursividade, marcadas pelo processo de formação dos termos, pelas categorias gramaticais, pelos enunciados definidores, pelos exemplos, referidos a formações discursivas heterogêneas, indicando a posição do sujeito lexicógrafo e o efeito leitor (NUNES, 2006; SILVA, 1996). Vejamos primeiro o par exclusão-inclusão, que chama nossa atenção, antes de tudo, pela pouca visibilidade que se tem de exclusão, considerando, por exemplo, o número de enunciados definidores, a presença-ausência de exemplos. 
exclusão (1550 DPPI II 32)

substantivo feminino

1 ato de excluir(-se)

2 JUR ato que priva ou exclui alguém de determinadas funções;exclusiva

3 MAR ato ou efeito de desligar um praça do serviço naval por má

conduta ou delito.

inclusão (1665 cf. AcSing)

substantivo feminino

ato ou efeito de incluir(-se)

1 estado daquilo ou de quem está incluso, inserido, metido, compreendido

dentro de algo, ou envolvido, implicado

em; introdução de uma coisa em outra, de alguém em um grupo etc. «i. de

uma carta num envelope >i. de um nome e, uma lista〉 i. de um indivíduo num $p$

artido político〉 ¿i. de um suspeito num processo criminal

$2 B$ política de integração plena de um indivíduo ou de um grupo na sociedade através de projetos que visam equacionar as dificuldades e carências que esse indivíduo ou grupo apresenta «i. digital〉 〈é preciso promover a $i$.

social;

3 (1926) HISTOL técnica de microscopia que consiste no prévio envolvimento d e um tecido ou órgão em parafinaderretida ou outro polímero, que, ao solidifi car-se, permite o corte do tecido ouórgão em finas lâminas

4 LÓG relação entre duas classes tal que os elementos constitutivos de uma se encontram entre aqueles da outra

5 MAT propriedade que possui um conjunto de ter todos os seus elementos contidos num outro conjunto

6 MINER corpo sólido (cristalizado ou vítreo), líquido ou gasoso cuja natureza é diferente do conjunto no qual ele está inserido (HOUAISS online).

Ao buscarmos o sujeito da ação de quem pratica ou sofre o efeito da exclusão e da inclusão, nesse movimento de palavra-puxa-palavra próprio da estrutura dos dicionários, ocorreu algo interessante. Encontramos um verbete para excluído, mas não para incluído, uma vez que este é derivado do verbo "excluir". Então, via excluso como sinônimo de excluído, chegamos a incluso, como veremos a seguir. 
excluído (sXV cf. FichIVPM)

adjetivo

1 que se excluiu

1.1 posto para fora, expulso \&foi e. do time de basquete por mau comportamento>

1.2 que foi omitido, deixado de fora 〈e. da lista dos convidados〉

sinônimos

excluso

incluso ( $s X V$ cf. FichIVPM)

adjetivo

1 que se inclui; incluído

1.1 metido dentro de; inserido, contido 〈documento i. numa carta〉

1.2 anexado, juntado (a outra coisa ou a um todo); incorporado, reunido

<item i. em um artigo 〈estar alguém i. num grupo>

1.3 que está envolvido em, que faz parte de; compreendido, abrangido «um indivíduo i. em vários crimes

1.4 encerrado, fechado, enterrado em 〈siso i. no osso〉

adjetivo e substantivo masculino REL

2 dizse de ou indivíduo dos inclusos, antigo grupo de religiosos que se encerravam em celas de ínfimas dimensões e nestas viviam como se enterrados (HOUAISS online).

Destacaríamos nesse funcionamento: 1. A questão do sujeito excluído e o outro em uma estrutura transitiva, sendo esse outro que estabelece, conhece, sabe dos limites e fronteiras para se estar dentro ou fora, bem como os modos de inclusão, observando, ainda, que excluído só tem como enunciado central a forma pronominal; 2. Uma assimetria e discrepância em relação à inclusão e ao sujeito incluído que pode ser pessoa ou coisa; 3. A construção de um referente discursivo (histórico-ideológico) como objeto imaginário, estabelecendo equivalência entre pessoas e coisas; 4. O caráter pronominal da exclusão-inclusão.

Indo por esse caminho de reflexão, podemos construir uma rede semântica de significação que irá nos dar uma compreensão discursiva da opacidade desses termos como noção, como categoria analítica do discurso da ciência, revelando-se, ainda, um observatório do funcionamento da ideologia, da relação entre a história das ideias e a história do processo de escolarização no Brasil: um discurso em que se (re)formula de forma aparentemente neutra, objetiva, um imaginário relativo a diferenças e desigualdades, criando condições para outros processos de individuação do sujeito urbano escolarizado. 
José de Souza Martins, em seu livro Exclusão social e a nova desigualdade (2007), afirma da perspectiva sociológico-política, e não econômico-social, que o que conta são as contradições, e diz de forma categórica que:

[...] não existe exclusão: existe contradição, existem vítimas de processos sociais, políticos e econômicos excludentes; existe o conflito pelo qual a vítima dos processos excludentes proclama seu inconformismo, seu mal-estar, sua revolta, sua esperança, sua força reivindicativa e sua reivindicação corrosiva (MARTINS, 2007,p. 14).

E alerta sobre a importância de se discutir esse termo/noção/conceito/categoria, considerado por ele vaga, vazia, imprecisa, de modo a evitar reducionismos, simplificações nos gestos de interpretação de uma sociedade complexa como a nossa.

Para Vera da Silva Telles (2006), a narrativa da exclusão não serve mais de referência explicativa uma vez que os jovens:

[...] realizam uma experiência da cidade tensionada entre a brutalidade das desigualdades e a sedução encantatória do moderno mercado de consumo, em um jogo ambivalente de possibilidades e bloqueios para o acesso a uma vida urbana ampliada (TELLES, 2006, p. 177).

E nos fala desses limites e fronteiras entre riqueza e pobreza como não sendo mais estanques, sendo muitas vezes mediados por uma rua, um quarteirão, tangenciando-se todo o tempo. Os trabalhos precários, instáveis, vulneráveis em shoppings, em clínicas médicas, odontológicas, como vendedor/a, atendente, secretário/a, segurança de hotéis, boates de luxo, motoboys, fazem com que os jovens circulem diariamente por espaços muito diferentes dos da família, do local de moradia. Podemos considerá-los excluídos? De quê? Por outro lado podemos considerá-los incluídos? Como?

Schaller (1996) trata do que chama de fenômeno da exclusão em termos de segregação, como marca de uma ruptura histórica, tendo como referência a França, face à precarização do trabalho, ao desemprego, à estigmatização das vítimas. Essa ruptura concerne, diz ele, apoiando-se em Touraine, à passagem de uma sociedade verticalizada para uma horizontalizada, em que se observa, como diz Telles (2006), a expansão dos circuitos de consumo de bens materiais e simbólicos que atingem mercados populares, articulando consumo, modos de vida, relações sociais. 
Outros autores irão buscar compreender não só a relação entre desigualdades sociais e educacionais, mas compreender o que há de específico na exclusão escolar, ou seja, nos mecanismos internos à escola para produzir a exclusão-inclusão, evidenciando repetições, apagamentos, silenciamentos, deslocamentos nessas lutas ideológicas de movimento entre o "dentro" e o "fora” que ali se travam, no interior de uma mesma sociedade.

Bordieu e Champagne (1998) irão falar em "práticas de exclusão brandas”.

A diversificação dos ramos de ensino, associada a procedimentos de orientação e seleção cada vez mais precoces, tende a instaurar práticas de exclusão brandas, ou melhor, insensíveis no duplo sentido de contínuas, graduais, imperceptíveis, despercebidas, tanto por aqueles que as exercem como por aqueles que são suas vítimas (BORDIEU e CHAMPAGNE, 1998, p. 222 - grifo dos autores).

Acácia Kuenzer (2002) ao analisar duas lógicas articuladas dialeticamente: a da “inclusão excludente", relativa ao mercado de trabalho, e a da "exclusão includente", relativa à educação escolar, fala de estratégias de inclusão nos diversos níveis e modalidades da educação escolar, que não correspondem a padrões de qualidade necessários à formação de identidades autônomas intelectual e eticamente, como: ciclos, progressão automática, classes de aceleração, cursos aligeirados de formação profissional.

[...] o conjunto das estratégias que apenas conferem "certificação vazia", e por isto mesmo, se constituem em modalidades aparentes de inclusão que fornecerão a justificativa, pela incompetência, para a exclusão do mundo do trabalho, dos direitos e das formas dignas de existência (KUENZER, 2002, p. 15 - grifos da autora).

Em relação à certificação, Dubet (2003) mostra como até 1960, na França, havia uma relação entre número de formandos e de empregos, sendo que estes não dependiam de qualificação escolar. Mas, a partir daí, com a massificação do ensino e a precarização do trabalho, o valor do diploma cresce em relação ao emprego, o que nos permite compreender um pouco mais esse esforço do aluno em ter de qualquer forma uma certificação mesmo que uma “certificação vazia”. Duas outras questões são apontadas por Dubet em relação a esses mecanismos de produzir exclusão no interior da escola: em primeiro lugar, a adoção dos chamados "métodos ativos" que exigem 
uma mobilização dos pais, quer dizer, de seus recursos e competências, no que as crianças e jovens pobres estarão em desvantagem; e em segundo lugar, a chamada meritocracia, que ordena, hierarquiza e classifica, sendo os alunos responsabilizados individualmente pelo fracasso, presente, por exemplo, no “aprender a aprender". Este pode ser um caminho para compreendermos um pouco daquele verbo pronominal “excluir-se”, atravessando a transparência da linguagem e a linearidade do sentido.

Luiz Carlos de Freitas vai falar na criação de um campo de exclusão subjetiva auto-exclusão, exclusão entre ciclos, trilhas de progressão continuada diferenciada em que a responsabilidade da exclusão recai sobre o excluído. Ele trabalha, então, com dois conceitos: o de internalização de custos e o de exclusão branda de Bordieu e Champagne (1998), já mencionado. Em relação ao primeiro, é a tomada de consciência dos custos econômicos da evasão e da repetência, para em seguida controlá-la. O outro conceito, como vimos, reforça as práticas de internalização da exclusão, controlando os custos sociais e políticos da repetência e da evasão.

\footnotetext{
Em um primeiro passo, a exclusão é internalizada (no sentido de que o aluno permanece na instituição escolar mesmo sem aprendizagem, ao contrário de quando era puramente eliminado da escola) e ganha-se clareza e controle sobre os seus custos econômicos (com Programas de Correção de Fluxo, Classes de Aceleração, Classes de Reforço etc.). Em um segundo momento, o custo pode ser externalizado, via privatização, por terceirização. Antes, os custos da repetência e da evasão eram informais, como um mal necessário, e faziam parte do próprio metabolismo de maneira não-racional (por exemplo, a defasagem idade/série), agora eles foram contabilizados e formalizados, sendo, portanto, passíveis de maior controle (correção de fluxo e equivalência idade/série) (FREITAS, 2008, p. 306).
}

Em termos de políticas de ensino de língua(s), as contradições vão ser trabalhadas por teorias que dão sustentação ao estabelecimento dessas fronteiras móveis e movediças que atravessam a sociedade brasileira em um momento marcado por uma ditadura (1964-1985) e pela redemocratização do país. Conjuntura essa em que se estabelecem alianças entre Ciência, Estado e Sociedade, via teorias linguísticas, como garantia de elaboração de políticas e práticas objetivas, neutras, transparentes, logo democráticas, em oposição à gramática normativa e prescritiva, considerada opressora, elitista, centrada apenas no escrito. Os linguistas eram críticos de um ensino do português considerado inadequado aos brasileiros que entravam na escola - um 
sujeito urbano pobre, agora, excluído - e, ao mesmo tempo, partícipes da construção dessas novas políticas públicas e de seu processo de didatização (SILVA, 2017).

Observamos, então, pelo funcionamento de relações de interdiscursividade, a produção de universos logicamente estabilizados (PÊCHEUX, 1990a), em que se constrói e se difunde um modo de dizer em relação a esse referente discursivo e a uma posição de sujeito e seu efeito leitor. Um trabalho simbólico e político intenso de construção e difusão no que concerne a um problema econômico e social que desliza para um problema educacional e linguístico, como prioridade nacional, como política de Estado.

Em um embate entre teorias linguísticas, algumas irão se tornar dominantes: a sociolinguística laboviana e a psicolinguística cognitiva, em uma leitura pragmática e funcionalista, calcada nos usos de língua dentro do arcabouço de uma ideologia da comunicação, e de uma ideologia da interação intersubjetiva em situações empíricas, a partir das quais o sujeito se desloca em direção a um universalismo de competências e habilidades, a serem medidas em avaliações de larga escala nacionais e internacionais. Movimento esse em que a língua portuguesa, em sua diversidade se torna variedade, em instrumento de comunicação e meio de expressão cultural, passível de ser gerida por um discurso tecnicista em que a falha, o equívoco não têm lugar. Mas, a ideologia é um ritual que sempre falha.

\section{O sujeito pobre: o discurso, o interdiscurso}

Do que estamos falando quando falamos, hoje, de sujeito excluído dentro e fora da Escola em termos de memória? Que gestos de interpretação estão aí presentes? Como no espaço de reformulação-paráfrase de uma formação discursiva se dão esses processos de individuação do sujeito urbano escolarizado sob a forma de sujeito de direito e de sujeito do conhecimento?

Em nosso país, essa relação entre discurso e interdiscurso no que se refere a esses limites e fronteiras móveis e movediças presentes nas relações sociais, em condições materiais de existência determinadas, tem como elemento estruturante da 
construção dos referentes pobreza e exclusão, a Escravidão, pensada no interior da ideologia da colonização: a escravização dos índios e a dos africanos e a sua libertação (MAMIGONIAN, 2017). Assim, sob a transparência da linguagem temos o caráter material do sentido das palavras e dos enunciados, indicando que o sentido não existe em si mesmo, que "uma palavra, uma expressão, uma proposição não tem um sentido que lhe seria "próprio", vinculado a sua literalidade" (PÊCHEUX, 1988, p. 161). Elas recebem seu sentido da formação discursiva, referida às formações ideológicas, na qual são produzidas.

Telles (2001), ao analisar o lugar que a pobreza ocupava no horizonte simbólico da sociedade brasileira em um Brasil urbano que se constituía na virada do século XIX, busca compreender como ela foi tematizada por cronistas, literatos, políticos, médicos, juristas, sanitaristas, engenheiros, dentre outros, para "cimentar o caminho do progresso", individualizando o que ela chama de tipos sociais.

[...] o vadio, o desempregado, o criminoso, o mendigo, o inválido, o louco, a criança abandonada. Tudo isso junto montava as figuras de uma pobreza que inquietava a sociedade. Mas se a miséria inquietava, era porque o retrato que dela se fazia exalava a ignorância e a incivilidade de uma gente que trazia na própria natureza, como vício de caráter, um passado que se queria superado (TELLES, 2001, p. 35).

Em nosso trabalho de tese, hoje livro (SILVA, 2015), também pudemos observar, tal como Telles, o que sustenta o estabelecimento desses limites e fronteiras da exclusão-inclusão no século XIX, em que se estabelecem categorias hierarquizadas e superpostas entre pessoas e não-pessoas, entre cativos, libertos e livres, e compreender alguns sentidos que continuam a significar em relação à construção dessa posição histórica de sujeito urbano escolarizado livre e pobre (FRANCO, 1974) e, agora, excluído. Quando analisamos o livro de José Ricardo Pires de Almeida, vemos a escola, que se estrutura junto com a Nação, significar como espaço de regeneração; e um aluno que é visto - e se vê - como alguém a ser regenerado, e não como aprendiz de um conhecimento ignorado.

As classes ocupadas com trabalhos manuais ou degradadas pelos hábitos ociosos ou viciosos parecem, em muitos casos, comprazer-se com a ignorância... Já se conhece como são os filhos destes pais: pálidos, fracos, malnutridos, trazem em seu rosto um descaramento precoce; instintos perversos 
já se apropriam do coração destes pequenos seres... (ALMEIDA, 1998, apud SILVA, 2016, p. 93-94).

A ignorância, aí, significava "falta" de moral, de bons costumes. "Ignorância" significava outras coisas além de saber ler e escrever, de dominar uma técnica, uma tecnologia. E quem era o "ignorante"? Era o escravo, o de cor, o de classe inferior, o órfão, o indigente, e, ao mesmo tempo, o ocioso, o vicioso, o vagabundo, o descarado, o depravado, o devasso, o imoral, fazendo parte deste fundo hereditário, herança de nossa barbárie. Era preciso, portanto, estancar a ignorância, enquanto fonte, não de desconhecimento das letras e das ciências, mas de vícios, crimes e misérias em uma relação entre formações discursivas heterogêneas.

Falar em inclusão/exclusão, em igualdade de oportunidades, em defesa das diferenças individuais ou de classes, hoje, significa, pois, em relação a um interdiscurso, a uma memória discursiva de uma sociedade colonizada e escravocrata. Assim, as teorias educacionais e linguísticas que vão ser difundidas no Brasil a partir da segunda metade do século XX, como as da deficiência linguística, da carência cultural, das diferenças linguísticas, do mercado simbólico, da educação compensatória, produzem inversões, deslocamentos e, ao mesmo tempo, repetições. Desencadeiam processos discursivos que sustentam as desigualdades, mesmo que de forma transformada, ou mesmo as aprofunda. Importante pensar, então, nessa convivência constante e tensionada aí existente.

Como diz Maria Helena Souza Patto (1988), analisando a teoria da carência cultural formulada nos Estados Unidos nos anos 1960 e introduzida no Brasil na década seguinte:

Num país em que a linha que divide classes é praticamente a mesma que divide etnias, essa crença [a da carência cultural] encontra grande receptividade e pode facilmente se transformar num caso de preconceito racial e social trasvestido de conhecimento científico (PATTO, 1988, p. 75).

Cury (2008), em seu artigo "A educação escolar, a exclusão e seus destinatários" reafirma esses sentidos trabalhando o discurso jurídico. Ele pensa a escola, na modernidade, como "lugar do direito ao saber e da cidadania" (CURY, 2008, p. 208), como dever do Estado. A educação escolar, segundo ele, aparece nos códigos legais 
como um direito subjetivo do indivíduo e um direito social do cidadão. Ele se ocupa em analisar, mais diretamente, a desigualdade social em relação a esse direito universal de apropriação de bens socialmente produzidos, como o conhecimento. E é nesse contexto mais amplo de análise que situa a categoria da "inclusão", que prefere denominar “inclusão excludente”. Cury toma, nesse artigo, a memória histórica como categoria analítica e o sujeito como foco desse trabalho de rememoração, para observar "como o ontem se inscreveu" na categoria da inclusão, da perspectiva do discurso jurídico.

[...] faz sentido perguntar sobre quem são os 'herdeiros' e/ou os reais atingidos pela deserdação desta destinação universal, ou melhor, pela privação dessa destinação universal da educação escolar como um direito específico (CURY, 2008, p. 210 - grifos do autor).

O primeiro texto que analisa é o da Constituição Imperial de 1824, em seu Artigo 179 que "reconhece o direito à instrução primária”, direito este que será, contudo, limitado por outro Artigo, quando estabelece quem tem direito a essa instrução ao considerar: "como cidadãos brasileiros os que no Brasil tiverem nascidos, quer sejam ingênuos ou libertos" (cf. GUIMARÃES, 1996). E vai mostrando esse movimento histórico em afirmar o direito e, ao mesmo tempo, estabelecer limites, fronteiras em relação a esses direitos para alguns brasileiros, como escravos, mulheres, pessoas com moléstias contagiosas.

\section{Para finalizar}

Esse trabalho possibilitou abrir espaços analíticos para compreender como se dá a relação entre língua/sujeito/história na divisão do trabalho de leitura e escrita na escola e na divisão técnica do trabalho na sociedade, analisando os deslizamentos de sentidos - efeitos metafóricos, ideológicos - presentes nos termos/noções pobre e excluído, que identificam e classificam o sujeito urbano escolarizado; e explicitar alguns conflitos, confrontos, resistências, apagamentos que se dão nesses processos de 
nomeação, de construção de referentes discursivos, de processos de individuação do sujeito.

Como dissemos anteriormente, a ideologia não é um ritual sem falha e há resistência sob diferentes formas. Historicamente, em termos de escolarização do português tivemos sempre presente o argumento da "falta": falta por parte do/da aluno/a, do/da professor/a, da escola, da estrutura familiar; todos agora devidamente quantificados, pelas avaliações nacionais e internacionais, que transformaram esses sujeitos em cifras, números, nesse deslizamento histórico, em se tratando da sociedade brasileira, entre coisas-pessoas-coisas. Uma falta que, pelo movimento da paráfrase e da polissemia, torna-se visível, legível, publicamente reconhecida como uma evidência.

Mas, por que não pensar essa falta como o lugar da falha, do equívoco, da possibilidade de rupturas, de transformações possíveis em que a diferença é constitutiva?

\section{Referências}

AUROUX, Sylvain. A revolução tecnológica da gramatização. Trad. Eni P. Orlandi. Campinas, Editora da Unicamp, 1992.

BORDIEU, Pierre; CHAMPAGNE, Patrick. Os excluídos do interior. Tradução Magali de Castro. In: NOGUEIRA, Maria Alice \& CATANI, Afrânio (Orgs.). Escritos de educação. Petrópolis: Vozes, 1998, p. 217-228.

CURY, Carlos Roberto Jamil. A educação escolar, a exclusão e seus destinatários. In: Educação em Revista, n. 48. Belo Horizonte, dez. 2008, 205-222.

DUBET, François. A escola e a exclusão. IN: Cadernos de Pesquisa, n. 119, 2003, p. 29-45. FRANCO, Maria Sylvia de Carvalho. Homens livres na ordem escravocrata, São Paulo, Ática. 1974.

FREITAS, Luiz Carlos de. A internalização da exclusão. In: Educação e Sociedade, vol. 23, n. 80. Campinas, setembro, 2002, p. 299-325. Disponível em <http://www.cedes.unicamp.br>. Acesso em 30/8/2017. 
GUIMARÃES, Eduardo. Os sentidos de cidadão no Império e na República no Brasil. In: GUIMARÃES, Eduardo; ORLANDI, Eni P. (Orgs.). Língua e cidadania: o Português no Brasil. Campinas/SP, Pontes,1996, p.39-46.

HOUAIS, A. Grande Dicionário HOUAISS online. Disponível em <http://houaiss.uol.com.br>. Acesso em 25/8/2017.

KUENZER, Acácia Zeneida. Exclusão includente e inclusão excludente: a nova forma de dualidade estrutural que objetiva as novas relações entre educação e trabalho. In: SAVIANI, Demerval (Org.). Capitalismo, trabalho e educação. Campinas: Autores Associados, 2002, p. 1-17.

MAMIGONIAN, Beatriz G. Africanos livres: a abolição do tráfico de escravos no Brasil. São Paulo, Companhia das Letras, 2017.

MARTINS, José de Souza. Exclusão social e a nova desigualdade. São Paulo: Paulus, 1997.

NUNES, José Hora. Dicionários no Brasil: análise e história do século XVI ao XIX. Campinas, SP: Pontes; São Paulo: Fapesp - São José do Rio Preto, 2006.

ORLANDI, Eni P. Interpretação: autoria, leitura e efeitos do trabalho simbólico. Petrópolis: Vozes, 1996.

PATTO, Maria Helena Souza. O fracasso escolar como objeto de estudo: anotações sobre as características de um discurso. In: Caderno de Pesquisa, No. 65. São Paulo, 1988: p. 72-77.

PÊCHEUX, Michel; GADET, Françoise. A língua inatingível. Tradução de Sérgio Augusto Freire de Souza. In: ORLANDI, Eni P. (Org.). Análise de discurso: Michel Pêcheux. Campinas/SP: Editora Pontes, 2011, p. 93-106.

PÊCHEUX, Michel. Análise automática do discurso (AAD-69). Trad. De Eni P. Orlandi. In: GADET, Françoise; HAK, Tony (Orgs.). Por uma análise automática do discurso: uma introdução à obra de Michel Pêcheux. Campinas/SP: Editora da Unicamp, 1990, p. 61-161.

. Discurso: estrutura ou acontecimento. Trad. Eni P. Orlandi. Campinas/SP: Pontes, 1990a.

. Semântica e discurso: uma crítica à afirmação do óbvio. Trad. Eni P.Orlandi... et al. Campinas/SP: Editora da Unicamp, 1988. 
PFEIFFER, Cláudia Castellanos. Sentidos na cidade: clichê e sujeito urbano. In: Rua, Campinas/SP, n. 3, 1998, p. 37-58.

SILVA, Mariza Vieira da. Manuais escolares e saberes linguísticos. In: Boletin de la sociedad espanõla de historiografia linguística - BSEHL, vol. 11, 2017,p. 209-224.

. História da alfabetização no Brasil: sentidos e sujeito da escolarização. Campinas/SP: Editora da Unicamp, 2015.

. O dicionário e o processo de identificação do sujeito-analfabeto. In:

GUIMARÃES, Eduardo; ORLANDI, Eni P. (Orgs.). Língua e cidadania: o Português do Brasil. Campinas/SP: Pontes, 1996: p. 151-162.

SCHALLER, Jean-Jacques. Le projet est un combat... Pour une mobilisation de tous les acteurs! 1996: p. 1-15.

TELLES, Vera da Silva. Mutações do trabalho e experiência urbana. In: Tempo Social, revista de sociologia da USP, v. 18, n. 1. São Paulo, junho de 2006, p. 173-195.

TELLES, Vera da Silva. Pobreza e cidadania. São Paulo: Editora 34, 2001.

Recebido em 17/o9/18.

Aprovado em 1o/11/18. 